\title{
Dimensions of quality revisited: from thought to action
}

\author{
Robert J Maxwell
}

It is some years since, in an article reviewing the state of quality assurance in Britain, ${ }^{1} \mathrm{I}$ argued that quality in health care is multidimensional. This was not a new proposition. Donabedian, for example, had recognised that patient satisfaction can often diverge from technical efficiency as perceived by the expert provider. ${ }^{2}$ As used to be said of one energetic surgeon, "His patients loved him and they died young." The two views of quality are clearly not identical: the methods for measuring them and the people best placed to judge them differ.

Although Donabedian and others had recognised multidimensionality, the dimensions of quality I described were, I think, a genuine step forward in describing and explaining six facets of health care quality (box 1). It is gratifying that they struck a chord and that they seem to have been useful, both practically and conceptually, at several different levels in the system. However, they are obviously not the last word on so complex and important a subject. The purpose of this article therefore is, firstly, to reflect on some of the ways in which the dimensions have been used since they were proposed (there may well be many other examples, but those given here are at least illustrative); then to revisit the concepts underlying them; and, finally, to argue that we must not let the search for quality become too intellectual, purist, and static: "the letter killeth, but the spirit giveth life." 3 Mark Twain remarked about the British weather that everyone in Britain talked about it, but nobody did anything about it. Let not the same be said of quality in British health care. After all, in recent years we even seem to have done something about the weather.

\section{Using the dimensions}

EAST ANGLIAN EXAMPLE

East Anglian has some claims to the title of flagship region in its early, bold attempts to explore the meaning of a managed market. It took the view that the NHS reforms were not an end in themselves but a means to an end. The end had to be, in some terms, health outcome. The region adopted the six dimensions of quality, slightly retitled to form the mnemonic EEEAAR, to express the corporate values underlying its definitions of health outcome. These values have been used consistently in East Anglian region for the past few years to underpin performance contracts between districts and region and between providers and purchasers and to tackle strategic issues (box 2). Hence, the explicit definition of corporate values helps to remind management and others that the drive to efficiency should not be at the expense of equity or the pursuit of accessibility (for example, reduced waiting lists and waiting times) at the cost of appropriateness (for example, high standards of emergency care and chronic care). It might be difficult to demonstrate the precise impact of the dimensions on quality of health care in the region. What they seem to have done is to provide a shared framework for discussion among "insiders" (managers and professionals at various levels and members of authorities and trusts) about intentions and performance.

\section{HEALTH ABACUS EXAMPLE}

The Health Abacus (box 3), a joint venture between South West Thames Regional Health Authority and the Office for Public Management, has been developed as a simulation of illustrative purchasing dilemmas and decisions for use by, for example, district health authority officers and members or district and family health services authorities that want to explore the complementarity of what they are doing.

The basic point behind the simulation is that decisions are about policy trade offs - not only, as Sir George Godber succinctly put it, 
"that an investment in some part of the service is at the expense of an effort given to something else, which others may think more deserving" but also about trade offs between underlying values. The most illuminating part of the abacus simulations is not the simulations themselves, fun as these are. It is in the debriefings afterwards, when the participants are challenged to reflect on (for example) what part equity or appropriateness has played in their simulated decision, versus the pursuit of greater efficiency, or what they considered to be acceptable to the public or the politicians. For this purpose the policy trade offs are deemed to be between the values represented by the six dimensions. By values, I mean our underlying assumptions about what matters in health care. Hence the Abacus

One of the first hospitals whose existence was threatened in East Anglian after the introduction of the internal market was Mundesley Hospital, a small, isolated, post-acute inpatient rehabilitation unit of 38 beds, which was used by patients from all over the region. Its closure had been threatened for many years, a decision which the managing health authority (Norwich) had deferred, given the strength of local feeling.

Once the internal market was introduced, this issue became the responsibility of several purchasing authorities, each responsible for determining the health needs of its respective population and placing contracts to meet them. Each authority was expected to address the issue of the kind of rehabilitation service it wished to purchase as a potential replacement for Mundesley Hospital.

In doing this each sought to apply the regional values (effectiveness, efficiency, equity, access, appropriateness, and responsiveness) to derive a solution which represented the best compromise or "trade off" between those values. For example, in framing a specification for an alternative pattern of service provision, Norwich Health Authority sought a service which was:

- Effective - care and treatment programmes would show evidence of reduced functional impairment, based on a system of clinical audit

- Efficient - there would be a reduction in acute hospital stay and increased throughput

- Accessible - within about $5 \mathrm{~km}$ (three miles) of the Norwich ring road, proximity to the major sources of referral being advantageous but not essential

- Appropriate - utilising an "individual patient programme" approach

- Responsive - ensuring progression to graduated self care and day care, as appropriate, and utilising a nationally accepted patient satisfaction methodology

- Equitable - ensuring that people with identical needs receive the same standard of care regardless of where in the region they lived or were treated.

Using the dimensions framework helped to clarify the underlying conflict between values as they applied in this case, particularly between effectiveness on the one hand and accessibility and responsiveness on the other. Unsurprisingly, the preferred solution for Norwich based on the application of these values was a relocated, consultant led, rehabilitation centre supported by a specialist community team.

In another authority in the region, meanwhile, a community provider unit undertook a similar analysis of the same issues, underpinned by an explicit use of the regional values, to prepare a business plan, arguing its case for establishing an entirely community based approach associated with its well developed "hospital at home" programme. This was accepted as the best available alternative to use of the remote and inappropriate Mundesley Hospital.

A satisfactory position has been reached whereby Mundesley Hospital can now be closed as a genuinely redundant institution, based on a series of explicit purchaser and provider analyses expressed in terms of the regional values. The result has not been to create a series of identical alternatives to Mundesley Hospital but a range of different solutions for different authorities, each based on a particular purchaser's interpretation of the regional values in the context of what constitutes a good rehabilitation service.

Box 2 East Anglian region's EEEAAR walues for rehabilitation services is a metaphor. What the players (in real life, members of a health authority) are doing is

Developed by Siân Griffiths, director of public health for South West Thames region, and Laurie McMahon from the Office for Public Management in 1991, the Health Abacus was designed to help members of that new region to understand better purchasing for health gain at a local level.

Its name was chosen to reflect the reality of purchasing, in that it was not about achieving simple health targets but much more about having to make policy trade offs. These may be between competing health needs, or alternative service configurations, or between criteria for improvements in health services, such as efficiency and access. It may also entail trade offs between health improvements and a whole range of "constraining" factors such as public preferences and the influence of professionals at provider level. Moving the beads on the wires of an abacus seemed to fit the way in which authorities would have to balance the level of achievement they require on each of their criteria for health gain.

The success of the prototype prompted the region to develop it for districts and family health services authorities, during which it attracted interest outside. Dr Griffiths explained, "We were using Health Abacus material for national conferences where it was seen by people from the NHS Management Executive. They were impressed enough to fund its development as a free standing pack that could be used by other health authorities to develop their purchasing skills."

The pack provides the basis for running a training day with a simulation of specific purchasing dilemmas and decisions. The start of the day is devoted to setting the managerial and public health contexts in which health authorities must work, which provides an opportunity for members to clarify their roles as purchasers and to understand the dynamics of their relationships with regulators, health and social care providers and general practitioners, and the public.

Participants then work to "sophisticate" the orthodox model of health policy making in which health needs are balanced against available resources. Once a much more realistic understanding of purchasing process, with all its dilemmas and trade offs has been established, the simulation stage begins.

The rules that govern the play are extremely simple since participants maintain their real board member roles and only the policy issues are simulated. These are highly realistic and have been designed to exploit the organisational and public health trade offs within the "abacus" of health gain, and if selected from the portfolio with care they can be used to explore real life dilemmas for the district or family health services authority.

For Laurie McMahon the Health Abacus is not a game: "It doesn't produce winners or losers and it is not a puzzle that has a right answer. People do enjoy the exercise and the simulation is good fun, but they are in their real roles and are using their real values to inform their judgements about how to achieve maximum health gain. There is some serious learning to be derived from that."

Box 3 Health Abacus 


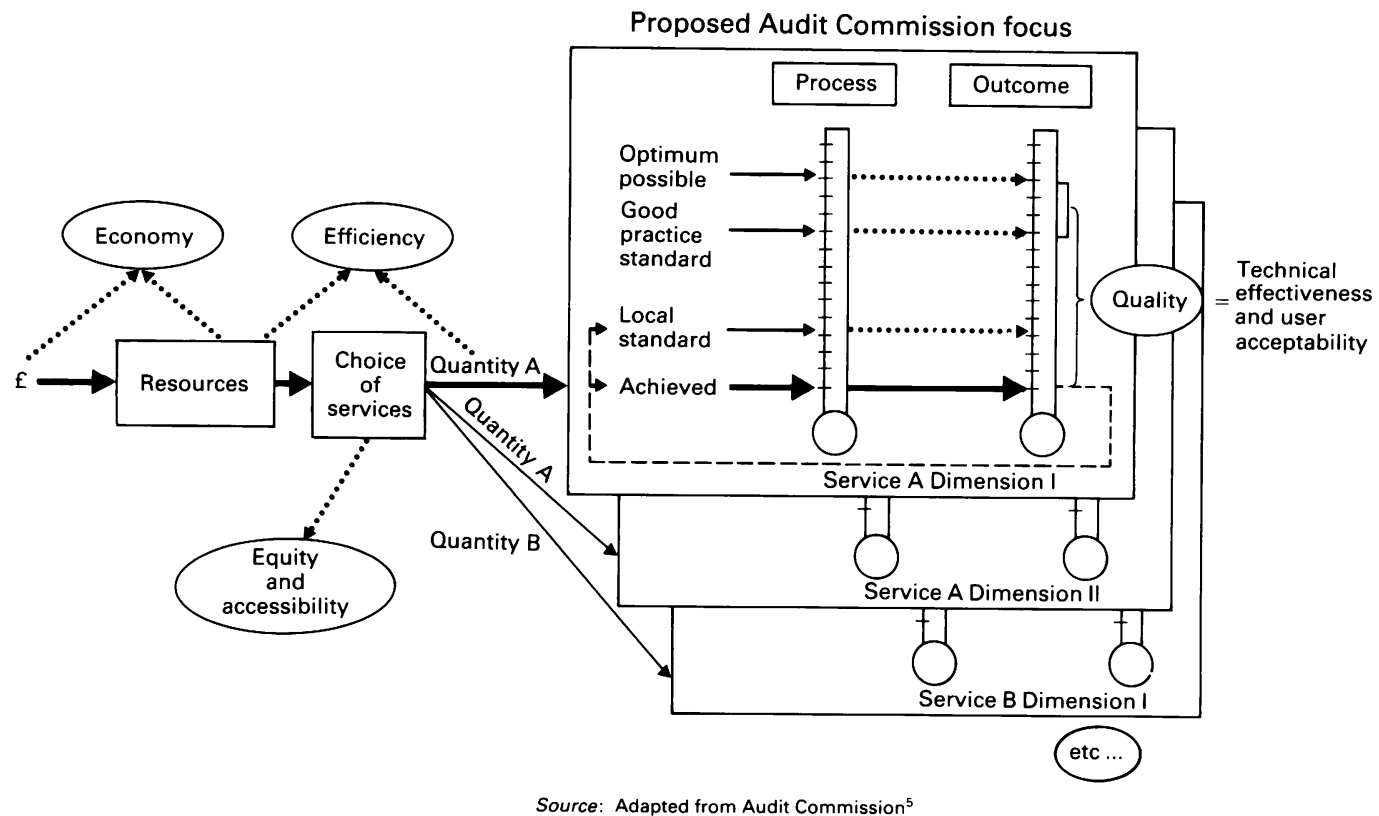

Conceptual framework for quality

Source: Adapted from Audit Commission

gaining insight into the nature of the trade offs between, for example, equity and efficiency or, say, acceptability and access.

The similarity with the East Anglian example is that both are concerned with core values. The difference is that Health Abacus is essentially developmental, encouraging people to be more reflective in a training situation. The East Anglian example is in a sense more prescriptive in that it uses the six dimensions to make the basis of regional strategy explicit.

\begin{tabular}{|c|c|c|c|}
\hline & US & $U K$ & Comments \\
\hline Effectiveness & +++ & ++ & $\begin{array}{l}\text { For many technical procedures the US system } \\
\text { is ahead in ingenuity world wide. The UK } \\
\text { system is more conservative, less well } \\
\text { equipped, and rather less "hooked" on } \\
\text { technology - sometimes wisely }\end{array}$ \\
\hline Acceptability & +++ & + & $\begin{array}{l}\text { For most US citizens American health care is } \\
\text { well ahead of Britain on the consumer } \\
\text { dimension - for example, explanation, } \\
\text { amenities }\end{array}$ \\
\hline Efficiency & + & ++ & $\begin{array}{l}\text { Both systems are inefficient in different ways. } \\
\text { The US system can be very efficient at the } \\
\text { institutional level but extremely extravagant at } \\
\text { the system level whereas the opposite is true in } \\
\text { the UK system, which costs less than half the } \\
\text { US system per head }\end{array}$ \\
\hline Access & ++ & ++ & $\begin{array}{l}\text { The systems have different virtues and vices. } \\
\text { The vice in the US system is the barrier of } \\
\text { payment, affecting the uninsured. That in the } \\
\text { UK is waiting for elective treatment and for } \\
\text { some other services (for example, geriatric } \\
\text { assessment) }\end{array}$ \\
\hline Equity & 0 & ++ & $\begin{array}{l}\text { To non-Americans the US system seems } \\
\text { obscenely inequitable, with some } 35 \text { million } \\
\text { uninsured, who may face financial ruin if they } \\
\text { need expensive medical care }\end{array}$ \\
\hline Relevance & + & ++ & $\begin{array}{l}\text { Though the US system has a high level of } \\
\text { provision and is sensitive to demand, it is } \\
\text { grossly skewed towards acute care. The UK } \\
\text { system is more balanced and is stronger in } \\
\text { primary and chronic care }\end{array}$ \\
\hline
\end{tabular}

Box 4 Comparison of quality of health care systems in United States and United Kingdom
AUDIT COMMISSION EXAMPLE

The Audit Commission has considered the six dimensions, along with various other references on quality (both in health care and in other sectors), in deciding where to position its own work. It was inclined at one stage to merge the dimensions of access and equity on the grounds that they were close enough not to be differentiated. I understand this argument, but I am not convinced by it - or at least not yet. This is a conceptual question to which I will return later. The main point, however, is that the commission found the idea of multidimensionality convincing and useful. It might well have taken a narrow view of its role as being to ensure that the NHS is efficient in converting inputs to outputs and hence in producing as many units of service as possible for a given public expenditure allocation. What it is doing instead is to concentrate its own work on technical quality (my effectiveness dimension) and on patients' views (the acceptability dimension) while recognising that this is only part of a fuller quality map. Because its concern is mainly with providers it has decided that these two dimensions are the ones to emphasise, along with efficiency. It is making the (bold) assumption that purchasers will take care of the other quality dimensions and is making this assumption explicit, showing how its work is expected to fit into a larger conceptual framework (figure). Indeed at a conceptual level this nicely illustrates the value of using several separate dimensions to decide where to concentrate efforts to improve quality.

EXAMPLES COMPARING INTERNATIONAL OR INTER-AREA PERFORMANCE

In my role at the King's Fund College I often find myself having to talk to overseas visitors at the start, or the end, of a visit to study various aspects of the NHS. I find the dimensions useful in arguing that, like a curate's egg, the NHS is good in parts. Relative to the United States, for example (box 4), our 
arrangements are strong on equity and are very low cost: our balance of services between primary and other levels of service is good, and we use our limited resources more efficiently and more relevantly. But relative to most Americans, a British citizen using the NHS receives a less consumer friendly service (the acceptability dimension). Americans living in Britain are likely to be struck by the neglected and dirty state of NHS premises and by the lack of time taken discussing with them what is going on. On the other hand, if the visitors come from central Europe they will certainly be less critical of these aspects. They nevertheless need to have a framework in mind for comparing what they see with what they know in their own nation's services. On the whole, what people should gain from international experience is not "solutions" to problems, since few are transferable and even fewer are panaceas. Rather, it is a deeper understanding of the strengths and weaknesses of their own system, seen within a framework of relevant values. That ought to make us all less complacent and, if we are genuinely bent on the pursuit of excellence, clearer about what to try to change and what to preserve.

Conceptually, of course, this applies just as much to comparisons between areas (or indeed between institutions) as to international comparisons. As an illustration, box 5 attempts to summarise the relative strengths and weaknesses of London's health services and to show how the recommendations of the
King's Fund's London Commission will provide a balanced strategy for reform.

\section{Revisiting the concepts}

The definition of the six dimensions (box 1) and precisely how many dimensions there ought to be are far less important than the acceptance of multidimensionality, the flavour of the dimensions, and of the policy trade offs among them. As remarked earlier, the Audit Commission seems likely to have eliminated one dimension by amalgamating access and equity, on the grounds that most inequities are about uneven access. For now, I prefer to keep both dimensions because there can also be other inequities that have nothing to do with access. For example, advocates for ethnic minorities argue with some justice that there is a systematic, if largely unconscious, bias in most public services against minorities that goes far beyond inequality of access. It has seemed to me, therefore, that we should retain the distinction between access and equity, despite the considerable overlap between the two.

In a technical sense this can be presented as an argument about orthogonality - literally the state of being rectangular. It is used more loosely by architectural planners to determine whether the dimensions selected to define spatial relationships are as independent of one another as possible. In deciding how to cluster hospital departments, for example, architects have to take account not only of frequency of

\begin{tabular}{|c|c|c|c|}
\hline & Strengths & Weaknesses & Recommendations ${ }^{*}$ \\
\hline Effectiveness & $\begin{array}{l}\text { As large a supply of } \\
\text { professional skills in acute } \\
\text { medicine and nursing, etc, as } \\
\text { anywhere in the world }\end{array}$ & $\begin{array}{l}\text { Primary and chronic care. } \\
\text { Many acute units too small } \\
\text { and too fragmented }\end{array}$ & $\begin{array}{ll}\text { (1) (3) } \\
\text { (2) (4) }\end{array}$ \\
\hline Acceptability & $\begin{array}{l}\text { Loyalty to particular } \\
\text { institutions and departments, } \\
\text { based on performance for } \\
\text { individual patients }\end{array}$ & $\begin{array}{l}\text { Few mechanisms for } \\
\text { community involvement and } \\
\text { local accountability. Still a } \\
\text { tradition of "noblesse oblige" }\end{array}$ & $\begin{array}{l}\text { Londoners to be } \\
\text { involved in their own } \\
\text { care }\end{array}$ \\
\hline Efficiency & Some very efficient units & $\begin{array}{l}\text { High costs inevitable in } \\
\text { London. Many units too } \\
\text { small and fragmented }\end{array}$ & (2) (3) \\
\hline Access & $\begin{array}{l}\text { Excellent access to specialist } \\
\text { services }\end{array}$ & $\begin{array}{l}\text { Poor access (for many } \\
\text { people) to primary care and } \\
\text { community based chronic } \\
\text { care. Limited hospital access } \\
\text { fo routine conditions }\end{array}$ & (1) (2) \\
\hline Equity & & $\begin{array}{l}\text { Inequity between inner and } \\
\text { outer London }\end{array}$ & (2) \\
\hline Relevance & & $\begin{array}{l}\text { Gross imbalance of services } \\
\text { relative to need. } \\
\text { Overinvestment in acute care } \\
\text { and underinvestment in } \\
\text { primary care and community } \\
\text { based care for chronic } \\
\text { conditions }\end{array}$ & (2) \\
\hline \multicolumn{4}{|c|}{$\begin{array}{l}\text { ^ Recommendations: } \\
\text { (1) Strengthen primary care, starting with various experiments } \\
\text { (2) Reduce numbers of general acute hospitals and their numbers of beds and increase their } \\
\text { outpatient care } \\
\text { (3) Establish more and better community based care for chronic conditions } \\
\text { (4) Concentrate tertiary referrals, postgraduate education, and research in four main groupings linked } \\
\text { to the main science schools of London University (Imperial College, University College, King's } \\
\text { College, Queen Mary College/Westfield) }\end{array}$} \\
\hline
\end{tabular}

Box 5 Summary of strengths and weaknesses of health services in London and King's Fund London Commission's recommendations for reform 
communication between one department and another but also of several other factors. In other words, the problem is multidimensional. To avoid "double counting" between different dimensions they need to be as independent (that is, uncorrelated) as possible. The same is obviously true of selecting and weighting indices of deprivation, as in the Jarman index. ${ }^{6}$ By analogy, the more distinct from one another are the quality dimensions that we identify, the more complete and balanced the profile of quality that they will give. Indeed, correlation is actively dangerous if one is trying in the end to derive a comprehensive system for measuring health care quality in a single language, rather than simply alerting people to multidimensionality. So the Audit Commission has a real point about the overlap between equity and access if we are trying to use the six dimensions to derive an accounting language for health gain. I am not sure that would be feasible. Certainly I do not see it as an immediate priority, but we should be alert to the dangers of double counting.

To date, the main benefit of the six dimensions seems to have been to expand and clarify people's thinking and to illuminate discussion about underlying assumptions and values - to make practitioners more reflective, in Schön's terms. ${ }^{7}$ The six dimensions have provided a taxonomy (or classification) of the dimensions of quality in the sense that Mintzberg provided one for management strategies. ${ }^{8}$ That is gratifying, but somewhat static.

Recognition of multidimensionality is helpful - along with Donabedian's classification of structure, process, and outcome - in finding ways of measuring quality and assessing progress in improving it. Box 6 illustrates what I had in mind. I am not aware of people yet having moved far in this direction, though it may be inherent in the Audit Commission's approach. The root idea is that the recognition of multidimensionality makes it far more possible to see where any specific criterion fits into a comprehensive, rounded view of quality. It also helps to show what aspects of performance are inadequately covered by present indicators and suggests where to turn to begin filling the missing part of the jigsaw. If, for example, information about relevance or equity is missing, that immediately suggests turning for enlightenment to people with suitable skills rather than to the technical expert in the specialty concerned. The alternative - all too often demonstrated in the historical record of NHS quality assurance initiatives - is a morass of indicators with little clarity about their purpose and their relative importance. People measure what is a measureable and collect the results like jackdaws, regardless of value or usefulness.

It is remarkable how extraordinarily complicated and confused things rapidly became once people start examining the quality of medical care. That is the justification for trying to maintain some underlying clarity of concepts, even though the attempt may be laboured and the results imperfect.

A crucial issue for clinicians and managers is to recognise that medicine has essential roles at the level of both the individual and the community. Previously I remarked that an honest concern about quality, however genuine, is not the same as methodical assessment based on reliable evidence. ${ }^{1}$

\begin{tabular}{|c|c|c|c|}
\hline & Structure & Process & Outcome \\
\hline Effectiveness & $\begin{array}{l}\text { Staffing level and skills } \\
\text { Equipment } \\
\text { Access to theatres, etc }\end{array}$ & $\begin{array}{l}\text { Workload (volume of } \\
\text { patients treated) } \\
\text { Compliance with protocols, } \\
\text { where relevant } \\
\text { Data based peer review } \\
\text { Infection and } \\
\text { complications rates }\end{array}$ & $\begin{array}{l}\text { Survival rates compared } \\
\text { with similar units for } \\
\text { matched cases }\end{array}$ \\
\hline Acceptability & $\begin{array}{l}\text { Is setting frightening or } \\
\text { reassuring? } \\
\text { What provision is there for } \\
\text { relatives (privacy for } \\
\text { counselling, overnight } \\
\text { accommodation)? }\end{array}$ & $\begin{array}{l}\text { Is explanation to relatives } \\
\text { required and recorded in } \\
\text { notes? }\end{array}$ & $\begin{array}{l}\text { Is there follow up of } \\
\text { patients and of relatives to } \\
\text { obtain their opinions and } \\
\text { suggestions for } \\
\text { improvement? }\end{array}$ \\
\hline Efficiency & $\begin{array}{l}\text { Avoidance of extravagance } \\
\text { in structure, equipment, } \\
\text { and staffing }\end{array}$ & $\begin{array}{l}\text { Throughput, staffing, etc } \\
\text { Admission and discharge } \\
\text { arrangements }\end{array}$ & Costs for comparable cases \\
\hline Access & & $\begin{array}{l}\text { How many patients } \\
\text { suitable for admission have } \\
\text { to be refused because the } \\
\text { unit is full? }\end{array}$ & $\begin{array}{l}\text { What acutally happens to } \\
\text { patients refused or delayed } \\
\text { admission because the unit } \\
\text { is full? }\end{array}$ \\
\hline Equity & & $\begin{array}{l}\text { Is there any evidence of } \\
\text { bias in who is admitted or } \\
\text { how they are treated? }\end{array}$ & $\begin{array}{l}\text { Is there any evidence of } \\
\text { bias in outcomes? }\end{array}$ \\
\hline Relevance & $\begin{array}{l}\text { Bearing in mind other } \\
\text { needs, is this service an } \\
\text { appropriate use of } \\
\text { resources at the current } \\
\text { activity and expenditure } \\
\text { level? }\end{array}$ & & $\begin{array}{l}\text { How much difference does } \\
\text { the unit make to survival } \\
\text { and health status, and for } \\
\text { whom? }\end{array}$ \\
\hline
\end{tabular}

Box 6 Assessing quality in an intensive care unit 
Equally, an honest concern for the individual patient, however genuine, is not enough, under conditions of resource constraint. Even the individual clinician needs to be aware of the impact on other patients of the ways he or she uses time and other resources. Equally, public health specialists and general managers need to recognise that a population is made up of individuals and that quality of health care functions at both levels. The six dimensions can be useful in enhancing this awareness because they actually bridge this gap $(J$ Mitchell, personal communication). Although (for the moment) they do not divide up neatly, some (for example, effectiveness and acceptability) have power mainly at the level of the individual clinical encounter. Others (for example, relevance and equity) apply mainly at the collective level.

Another insight that may be helpful - even though it adds to the complexity - is to recognise the distinction between different levels of performance standard. The main point of measuring performance is to find ways of improving it. Evidence that it can be improved may well come from comparisons with other similar units or with the past record of one's own unit. Or it may come from a compelling piece of analysis and a pilot project. Or, at a higher level of theoretically attainable performance, there may be a definable optimum that represents an absolute constraint within the limits of available technology. Thus a hierarchy of performance levels can be envisaged, with a series of rising steps between current performance and a theoretical optimum (box 7). This would help to indicate where the greatest unexplored potential for improvement lies and at the same time focus on what the immediate targets ought to be.

- Theoretical optimum, within current technologies

- Known attainable level - that is, achieved somewhere, under realistic operating conditions

- Current target level - that is, realistically attainable on current plans

- Present performance level - showing variations

Box 7 Stepped levels of performance (applicable within any dimension of quality, to patient episode, or to health and health care of community)

\section{Putting the dimensions to use}

I have already commented on the danger of taking the six dimensions too literally whatever else they are, they are not the last word on the definition of quality but more of a starting position. An even greater danger, however, is to separate them into an abstract box marked "quality" as distinct from making them work for their living in the rough and tumble of NHS clinical and managerial life.

There is a similar danger with medical audit. Audit has suddenly become a widespread, obligatory activity, into which some clinicians put large amounts of time and effort. All too often that effort is not translated into action because only the enthusiasts are at the audit meetings, or because those who attend do not control all the resources necessary to introduce change, or because of some other reason. Should this continue, the enthusiasts are bound to become discouraged and audit be discredited.

These concepts and activities are not ends in themselves but means to ends. The end must be as high a quality of health care as can possibly be achieved within the resources available. Because this is a complex objective involving trade offs I would argue that the slightly tortuous thinking about concepts illustrated by the six dimensions is necessary. But it is certainly not sufficient. More fundamentally, it is absolutely essential that everyone involved has a passionate, shared commitment to the pursuit of quality.

If there is a Japanese secret, this is it. Quality is not achieved by inspection at the end of the production line nor can it be imposed from above. It is result of the shared aspirations and concerted efforts of all those involved, for whom it is a higher priority than any personal interest. Thus quality in a service such as health care requires eight oriented actions, as follows.

(1) Commitment to excellence for those reliant on the service - excellence judged by those who rely on it as well as by technical experts.

(2) Translation of good ideas into action, often by small incremental, persistent steps rather than by large leaps, and always tested against external indicators of performance (such as, in the commercial sector, market share and consumer expectations).

(3) Emphasis on team rather than individual performance since service depends on a combination of skills, not just on one individual or discipline acting alone.

(4) Systematic elimination of waste and of barriers to, and flaws in, high performance: excellence may be hard to define, but failures that are remediable can be much more easily identified and acted on.

(5) Recognition that every job involves responsibility (individual and collective) not only for doing the job well but for continually finding ways to do it even better.

(6) Use of concepts (like the six dimensions and measurements of performance) diagnostically to determine when and for whom intervention to raise quality is justified and to assess the impacts of these interventions.

(7) Development of action oriented measurement systems (as in box 6) that test progress and hence support continuing improvement.

(8) Determination to try to see quality initiatives always in the broader context of quality in the system as a whole. Otherwise there is a danger that any initiative will be at the expense of an unrecognised loss of quality elsewhere. As John Ruskin said in another context, "There is only one way of 
1 Commitment to quality for those served

2 Translation of good ideas into action, usually by persistent, small steps and tested against external indicators of performance

3 Emphasis on team performance

4 Systematic elimination of waste, flaws in performance, and barriers to good performance

5 Recognition of every staff member's dual responsibility - that is, to do the job well and to find ways to do it better

6 Diagnostic use of quality concepts (for example the six dimensions) to determine when to intervene to raise quality

7 Continual measurement of progress in order to support improvement

8 Viewing particular quality initiatives within the broader context of quality in the system as a whole

Box 8 Eight laws of implementing quality seeing things rightly, and that is seeing the whole of them."

It seems to me essential that we add to the conceptual understanding of the nature of quality in health care a determined orientation to action, an addition perhaps, of these eight actions (box 8) to the existing six dimensions.

1 Maxwell R. Quality assessment in health. BMF 1984; 288:1470-2

2 Donabedian A. The definition of quality and approaches to its assessment. Ann Arbor, Michigan: Health Administration Press, 1980.

3 Holy Bible. Corinthians II iii, 6.

4 Godber G. Maurice Bloch Lecture. Glasgow: University of Glasgow Press, 1976.

5 Audit Commission. Minding the quality: the Audit Commission's role in promoting quality in the NHS (in press).

6 Jarman B. Identification of underprivileged areas. BMF 1983;286:1705-9.

7 Schön DA. The reflective practitioner. London; Temple Smith, 1983 .

8 Mintzberg H, Waters JA. Of strategies, deliberate and emergent. Strategic Management fournal 1985;6:257-72. 